\title{
Fraser Syndrome: Case Report with Review of Literature
}

\author{
Saruban Pasu ${ }^{1 *}$, Luna Dhir ${ }^{2}$, Sarah Mackenzie ${ }^{3}$, Graham Thompson $^{3}$ \\ ${ }^{1}$ Moorfields Eye Hospital NHS Foundation Trust, London, England; ${ }^{2}$ Chelsea and Westminster Hospital, London, England; ${ }^{3}$ Moor- \\ fields at St. George's Hospital, Duke Elder Eye Centre, Tooting, London, England. \\ Email: sarubanp1@gmail.com
}

Received September 26 ${ }^{\text {th }}$, 2011; revised October 23 ${ }^{\text {rd }}$, 2011; accepted November $3^{\text {rd }}, 2011$.

\begin{abstract}
Fraser syndrome is a rare autosomal recessive multisystem disorder with a reported incidence of 0.043 per 10,000 live born infants and 1.1 in 10,000 stillbirths [1]. The condition is characterised by cryptophthalmos, cutaneous syndactyly, laryngeal and genitourinary malformations, craniofacial dysmorphism, orofacial clefting, musculoskeletal anomalies and mental retardation. The diagnosis can be made on prenatal scans, post natal clinical examination or on autopsy findings. We present a case of Fraser syndrome and review of the ocular manifestations of this condition.
\end{abstract}

Keywords: Cryptophthalmos, Fraser Syndrome

\section{Case History}

A one day old male infant was referred to the ophthalmology department for assessment of a fused right upper and lower eyelid. He was the first child born to nonconsanguineous parents of south East Asian origin. He had a birth weight of $2.8 \mathrm{Kg}$ and was born via vaginal ventouse delivery at $39+2$ weeks. Antenatal scans at 20 weeks had revealed unilateral right renal agenesis (see Figure 1(a)). An apparently normal left kidney was seen at this stage (see Figure 1(b)). No other abnormalities were noted on antenatal scanning.

Clinical examination revealed a normal anterior and posterior segment of the left eye. Right complete cryptophthalmos was noted with a palpable eyeball beneath (see Figure 1(c)). Systemic examination findings were an umbilical hernia, widely spaced fontanelle, bulbous nose and clinodactyly of the right fourth and fifth toes. The genitalia were normal, and no hypertelorism or orofacial clefting were noted. Further ultrasound scans and biochemical investigations showed the left kidney to be cystic, dyplastic and poorly functioning.

An MRI orbits and brain confirmed right cryptophthalmos (see Figure 1(d)).

A diagnosis of Fraser syndrome was made based on the clinical findings.

\section{Discussion}

The earliest reports of what is now known as cryptoph- thalmos (hidden eye) date back to the first century A.D. Pliny the Elder described the Lepidus family in which three children were born with a membrane over the eye, typical of this rare anomaly.

The term cryptophthalmos was introduced by Zehender [2] et al. in 1872 who described a child whose eyes were covered by continuous sheets of skin from forehead to cheek, associated with additional malformations including hypertelorism, syndactyly, abnormal genitalia, umbilical hernia, anal stenosis and hoarse voice.

George Fraser [3] in 1962 was the first to group these features together under the term "cryptophthalmos syndrome". In fact, cryptophthalmos is not always a feature of this syndrome, and thus, the eponym Fraser syndrome is preferable for the condition.

Fraser syndrome is a multiple malformation syndrome with a probable autosomal recessive inheritance. It may be caused by mutations in two genes FRAS1 [4] (chromosome 4) and FREM2 [4]. The FRAS1 extracellular matrix protein regulates epidermal-basement membrane adhesion and organogenesis during development. The FREM2 gene (chromosome 13) encodes the FRAS1related extracellular matrix protein 2 .

Thomas et al. in 1986 were the first to publish diagnostic criteria (see Table 1) for Fraser syndrome. The criteria were based upon a study of 124 cases. Two major criteria and one minor criterion or one major and at least four minor criteria were required for the diagnosis of 


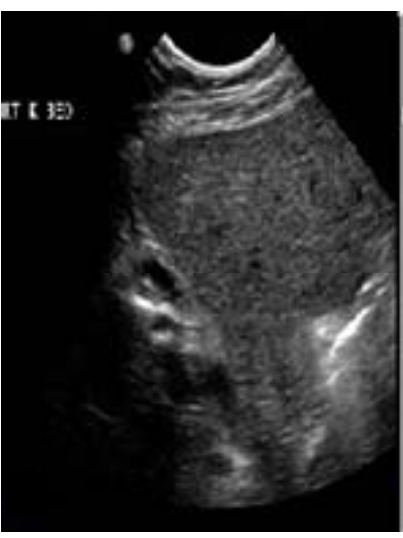

(a)

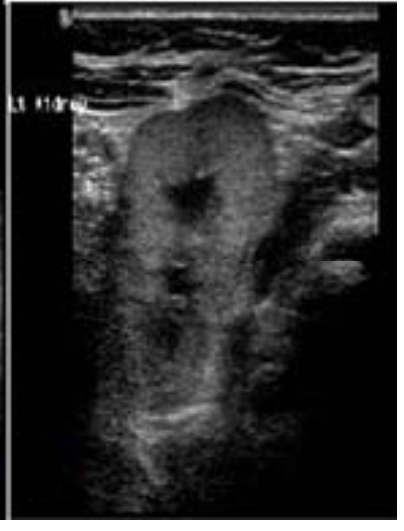

(b)

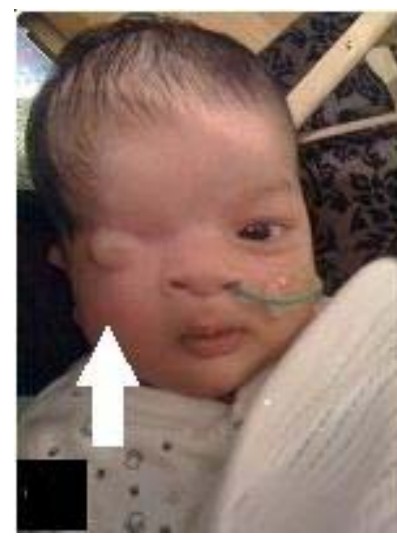

(c)

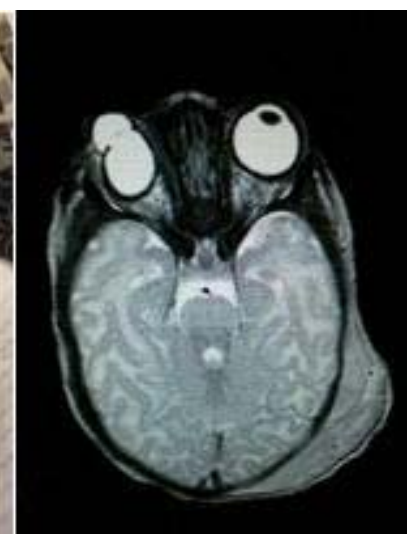

(d)

"Written consent from the patient's mother has been obtained and she is happy to be contacted on ferhatuddin@hotmail.com

Figure 1. (a) Absent right kidney; (b) Apparently normal left kidney on antenatal ultrasound scan; (c) Clinical photograph showing right eye complete cryptophthalmos; (d) T2 weighted axial MRI brain and orbits showing absence of right eye crystalline lens with cystic appearance to right eye anterior chamber. Extradural haematoma following ventouse delivery is also present.

Table 1. Diagnostic criteria for Fraser syndrome: two major criteria and one minor criterion or one major and at least four minor criteria were required for the diagnosis of Fraser syndrome. Asterisks mark the malformations present in our case.

\begin{tabular}{cl}
\hline & Cryptophthalmos * \\
Major & Syndactyly \\
Criteria & Abnormal genitalia \\
& Sib with Fraser syndrome \\
& Congenital malformation of nose * \\
& Congenital malformation of ears \\
& Congenital malformation of larynx \\
Minor & Cleft lip +/- palate \\
Criteria & Skeletal defects * \\
& Umbilical hernia * \\
& Renal agenesis * \\
& Mental retardation \\
\hline
\end{tabular}

Fraser syndrome [5].

The patient we described fulfils the criteria for a diagnosis of Fraser syndrome. These criteria helped differentiate Fraser syndrome from isolated cryptophthalmos.

Feldman et al. reported the first prenatal detection of Fraser syndrome in 1985. Their diagnosis was based on microphthalmia and hydrocephalus at 18 weeks of gestation, with a previously affected sibling [6].

Slavotinek [7] et al.'s work in 2002 aimed to validate the published diagnostic criteria and delineate the phenotype associated with this syndrome. Based on their review of 117 cases, cryptophthalmos was present in $88 \%$ of cases (unilateral in $27.4 \%$, bilateral in $47.9 \%$ ). This is consistent with previous reports, Thomas et al. [5] reported 85\% and Gattuso et al. [8] 93\% (unilateral 25\%, bilateral 57\%).

Numerous ocular manifestations of Fraser syndrome have been reported. The findings from the Slavotinek review are summarised in Table 2.

Francois' [9] review of 43 cryptophthalmos cases lead to this ophthalmic sign being divided into 3 groups.

Complete (typical) cryptophthalmos is usually bilateral structure with a sheet of skin running from forehead toand is characterised by replacement of normal eye lid

Table 2. Other ocular complications in Fraser syndrome.

\begin{tabular}{ll}
\hline Tongue of hair extending from scalp to lateral eye brow & $34.20 \%$ \\
Absent eye lashes & $29.10 \%$ \\
Coloboma of eyelid & $17.90 \%$
\end{tabular}

Groove in frontal bone/furrow to forehead/temporal depression $8.50 \%$

Microphthalmia

$21.40 \%$

Anophthalmia

$6 \%$

Corneal opacification/ corneal clouding/sclerocornea

$10.30 \%$

Microcornea /absence of the cornea/corneal epithelial defect $\quad 2.60 \%$

Abnormal anterior chamber/absence of the anterior structures $\quad 5.10 \%$

Hypoplasia of the optic nerve/atrophy of optic nerve $\quad 5.10 \%$

Symblepharon /oculopalpebral synechiae $\quad 14.50 \%$ 
cheek. There can be absence or poor development of the eyebrows, eyelashes, gland structures and conjunctival sac. The skin is adherent to the underlying cornea. Microphthalmia, symblepharon and abnormalities of the anterior chamber are common.

Incomplete (atypical) cryptophthalmos refers to rudimentary lid structures that are present with small conjunctival sacs placed laterally, Small palpebral fissures, micophthalmia and symblepharon [10].

Abortive cryptophthalmos or congenital symblepharon described an upper lid without a well defined margin that is adherent to the cornea. Slavotinek also suggests symplepharon is part of the ocular manifestations of Fraser syndrome [7].

We suggest utmost vigilance when clinicians are en countered with one fetal anomaly on antenatal ultrasound. Rare multisystem disorders like Fraser syndrome should be considered, so adequate parental counselling can be delivered.

\section{Literature Search}

A MEDLINE search covering the years 1950 to the present was conducted using the following terms: Fraser syndrome, cryptophthalmos syndrome, and cryptophthalmos. Articles cited in the reference lists of other articles were also searched.

The authors declare no conflicts of interest.

\section{REFERENCES}

[1] M. Narang, M. Kumar and D. Shah, "Fraser-Cryptophthalmos Syndrome with Colonic Atresia," Indian Journal of Pediatrics, Vol. 75, No. 2, 2008, pp. 89-91. doi:10.1007/s12098-008-0030-9

[2] W. Zehender, "Eine Missgeburt mit Hautueberwachsenen
Augen oder Kryptophthalmus," Klin Monatsbl Augenheilkd, Vol. 10, 1872, pp. 225-234. doi:10.1007/s12098-008-0030-9

[3] G. R. Fraser, “Our Genetical 'Load': A Review of Some Aspects of Genetic Variation,” Annals of Human Genetics, Vol. 25, 1962, pp. 387-415.

[4] I. Smyth and P. Scambler, "The Genetics of Fraser Syndrome and the Blebs Mouse Mutants," Human Molecular Genetics, Vol. 14, No. 2, 2005, pp. R269-274. doi:10.1093/hmg/ddi262

[5] I. T. Thomas, J. L. Frias, V. Felix, L. Sanchex de Leon, R. A. Hernandex and M. C. Jones, "Isolated and Syndromic Cryptophthalmos,” American Journal of Medical Genetics, Vol. 25, 1986, pp. 85-98. doi:10.1002/ajmg.1320250111

[6] E. Feldman, E. Shalev, E. Weiner, H. Cohen and H. Zuckerman, "Microphthalmia B Prenatal Ultrasonic Diagnosis: A Case Report,” Prenatal Diagnosis, Vol. 5, 1985, pp. 205-207. doi:10.1002/pd.1970050307

[7] A. M. Slavotinek and C. J. Tifft, "Fraser Syndrome and Cryptophthalmos: A Review of the Diagnostic Criteria and Evidence of Phenotypic Modules," Journal of Medical Genetics, Vol. 39, 2002, pp. 623-633. doi:10.1136/jmg.39.9.623

[8] J. Gattuso, M. A. Patton and M. Baraitser, "The Clinical Spectrum of Fraser Syndrome: Report of Three New Cases and Review,” Journal of Medical Genetics, Vol. 24, 1987, pp. 549-555. doi:10.1136/jmg.24.9.549

[9] J. Francois, "Syndrome Malformatif avec Cryptophthalmie,” Annals Genertics Medical Gemellol, Vol. 18, 1969, pp. 18-50.

[10] D. J. Brazier, S. J. Hardman-Lea and J. R. O. Collin, "Cryp- tophthalmos: Surgical Treatment of the Congenital Symblepharon Variant," British Journal of Ophthalmology, Vol. 70, 1986, pp. 391-395. doi:10.1136/bjo.70.5.391 